\title{
En busca de una definición genérica: los cuentos espiritistas de Octavio Mancera
}

\author{
In search of a genre definition: \\ Octavio Mancera's spiritualist short stories
}

\author{
Diana Vanessa Geraldo Camacho \\ Universidad Nacional Autónoma de México, \\ Instituto de Investigaciones Filológicas, \\ Seminario de Edición Crítica de Textos \\ dgeraldo01@gmail.com
}

\begin{abstract}
RESUMEN: En este trabajo exploro la naturaleza genérica de dos cuentos del escritor mexicano Octavio Mancera: "Caridad" y "Un crimen", ambos publicados en Cuentos diáfanos (1897), su única obra de narrativa breve. Debido al carácter multifacético del libro, decidí estudiar los cuentos de corte fantástico, como los denomina el propio escritor. La propuesta del artículo es que son relatos que se llaman fantásticos, pero en realidad su discursividad narrativa apunta al género maravilloso, en su peculiar formulación espiritista. Por ello, formulo una nueva terminología teórica para estudiarlos: el realismo espiritista. En busca de una definición, en este artículo analizo esos textos y ofrezco una lectura interpretativa de la categoría genérica a la que responden.
\end{abstract}

\author{
Palabras Clave: \\ Octavio Mancera; \\ cuento fantástico; \\ cuento maravilloso; \\ géneros literarios; \\ realismo espiritista; \\ literatura decimonónica.
}

KEYWORDS:

Octavio Mancera:

Fantastic tales;

Magic realism;

Literary genres;

Spiritist realism; 19th-century literature.
ABSTRACT: This essay examines the genre of two short stories by the Mexican writer Octavio Mancera: "Caridad" and "Un crimen," both published in Cuentos diáfanos (1897), his only collection of short narratives. Due to the multi-faceted character of this book, I chose to narrow my study to these texts which the author called fantastic tales. I question this genre placement arguing from their discursive narrative that, although termed fantastic, they belong more fittingly to magic realism because of their peculiar spiritist formulation. I propose the term spiritist realism as a new theoretical terminology for the study of these texts. In search of a definition, this article analyzes these two 
stories through an interpretative reading of the genre category to which they respond..

recepción: 30 agosto 2019

aceptación: 3 diciembre 2019

En 1897, la empresa tipográfica de la Revista Militar Mexicana publicó el libro Cuentos diáfanos, con el expresivo, y quizá paradójico, subtítulo "Cuadros realistas". Su autor, Octavio Mancera, un coronel mexicano que era redactor y colaborador constante de la publicación, ingresaba en el ambiente literario con su primera obra. Frente a los escritores consagrados, el novísimo literato, tal vez reconocido por algunos lectores como militar y periodista, pero no como cuentista, hacía su revelación pública apadrinado por su amigo y colega de la milicia Heriberto Frías, quien con generosidad escribió el prólogo de la obra, presentó al joven e hizo lo que podría considerarse el primer estudio crítico de sus relatos. Así se expresó Frías del novel narrador:

Octavio Mancera es un joven poeta, poeta de sentimientos exquisitos y espontáneos, poeta verdadero, sin ficción laboriosa, sin máscaras de sentimentalismos de moda ni refinamientos exagerados hasta el ridículo [...]. Basta tratar a Octavio para comprender cómo su temperamento aparece en los perfiles hermosísimos de sus personajes descritos al correr de una pluma elegante y naturalista [...]. No se ciñe a determinados asuntos, no puede asignársele escuela alguna (Frías ápud Mancera: III-IV y v).

Como escritor, sigue diciendo Frías, "Mancera lee, estudia, medita, crea, escribe, corrige, torna a corregir, pule y cincela" (xvI). Frías explica, además, que en Cuentos diáfanos "no hay convencionalismo, ni oropel: ese oropel de la dorada y fútil palabrería decadentista, tan sonora, tan retumbante, tan vacía y tan ilógica" (VI). De acuerdo con este repertorio de cualidades, Mancera no es decadentista ni pertenece a ninguna escuela, aunque bien puede ser valorado como naturalista — una tendencia, por cierto, no muy bien recibida a fin de siglo-, aunque sigue las modas momentáneas. Los comentarios de Frías son una respuesta a las tensiones literarias finiseculares que estaban en pleno auge cuando apareció Mancera 
en el mundo literario mexicano; ese mismo año, por ejemplo, Bernardo Couto publicó Asfódelos, y la polémica en torno al Decadentismo estaba en fuerte agitación. En ese ámbito de conflictivas definiciones, Mancera surge sin escuela, calificado únicamente como un autor original con una obra multifacética, particular en su poética, individual en su expresión, aunque variada en sus técnicas y recursos; es, según este bosquejo, un joven talento que pronosticaba preciados logros para las letras mexicanas.

Me he detenido en retomar los comentarios de Frías porque es muy poco lo que hasta ahora se sabe de Mancera, pues son breves y escuetas las notas dispersas que se encuentran sobre su persona y su obra. Aunque la presentación de Frías puede apreciarse hiperbólica y en un tono exaltado, también es ilustrativa y sugerente, ya que permite conocer la opinión de un literato decimonónico - que, aunque era una figura un poco disidente en el ámbito cultural de su época, ya contaba con un buen renombre después de la aclamada publicación de Tomóchic (1893-1895)—, sobre la figura y la obra del naciente escritor.

Ahora bien, el libro de Mancera tiene un carácter híbrido, como señaló Frías. El volumen se compone de diez relatos, los cuales responden a los preceptos estéticos del Modernismo: prosa culta y refinada, con abundantes metáforas, alusiones sinestésicas, mucha adjetivación poética, constante recurrencia a símbolos asociados a la naturaleza, como las flores, el cielo, la noche, los animales, el jardín, etc. Algunos de los temas más destacados en estos cuentos son: la creación artística y sus vínculos con otras artes, como la pintura y la música; el poder del sueño; las muchas variantes del amor en el ser humano; la constitución psicológica y sentimental de los individuos; el espiritismo y sus alcances científicos; la Ciudad de México; los tipos sociales y los problemas de justicia (el matrimonio por conveniencia, las violaciones, la pobreza, la violencia social, los asesinatos, la falsa sociedad, el condicionamiento biológico y económico de los ciudadanos); el erotismo; el hipnotismo y la catalepsia; las debilidades anímicas del hombre y otros temas más relacionados con asuntos religiosos o de creencias. Su obra, en fin, tiene un carácter multifacético, que coincide con el eclecticismo y la hibridación genérica tan común en las letras decimonónicas. Por último, no quiero dejar de comentar que algunos de los géneros que se hallan en su narrativa breve son: la leyenda 
y el cuento fantástico (ambos de tendencia romántica), la novela corta, el cuento de crítica social, el cuento modernista, al estilo de Manuel Gutiérrez Nájera, y el cuento gótico.

De todo el conjunto, dos ostentan el paradójico subtítulo de "fantástico". Me refiero a los textos titulados "Un crimen" y "Caridad". Y si utilizo tal calificativo es porque en la portada se leía Cuentos diáfanos. / (Cuadros realistas), definición que por supuesto choca con la posible clasificación en el género fantástico de esos relatos. Si se consideran únicamente los subtítulos, se advierte que es un libro de cuadros realistas en el que hay un par de cuentos fantásticos, que por ende también tienen una naturaleza afín al realismo y por eso están incluidos ahí. A pesar de que puede asegurarse que en la adjetivación hay un titubeo genérico o una contradicción de conceptos, me parece que el uso del término realista es congruente con la noción de género que cultiva Mancera. Esta afirmación, quizá también contradictoria, es el asunto que trataré de demostrar con el análisis de los relatos elegidos.

\section{"Caridad": primer acercamiento crítico}

Antes de comenzar a examinar los cuentos haré un par de acotaciones. "Caridad" se publicó por primera vez en la Revista Militar Mexicana con el título "Después de la batalla". ${ }^{1}$ En 1897, poco después de que ya estuviera en circulación el libro, el texto volvió a reimprimirse en la revista, pero con la siguiente aclaración: "Caridad. Del libro Cuentos diáfanos de Octavio Mancera". Este proceso de reproducción de textos, después de publicados en volumen, era poco frecuente en la antepasada centuria.

En cuanto a la categoría genérica del cuento, como se sabe, abundan las definiciones sobre la literatura fantástica y las clasificaciones de sus temas. Cuando se estudia la literatura fantástica del siglo Xx se puede encontrar con relativa facilidad un listado amplio de críticos que ofrecen la pauta o la guía para su comprensión. Por el contrario, al hablar de las letras decimonónicas el asunto cambia, y no por ausencia de trabajos o

1 Esta información se expuso en la propia revista; sin embargo, en la búsqueda que hice de todos los textos publicados por Mancera en esa publicación no localicé tal versión. 
de especialistas, sino por la propia naturaleza de esa tradición literaria. La literatura del siglo xIX de corte fantástico no coincide con los conceptos más o menos actuales que se han planteado sobre este género. En los decimononos hay más bien lo que Belem Clark denomina "eclecticismo", que consiste en el encuentro y fusión de corrientes estéticas, de intereses de carácter social, de afinidades con los grupos de escritores, de convenciones genéricas y semánticas de la época; así lo indica la estudiosa: "En cuanto a la función literaria, su arranque estuvo íntimamente relacionado con otras disciplinas [...] fueron los mismos hombres los que elaboraron y entremezclaron los discursos —literario, histórico, científico y político-, de ahí que con facilidad el investigador podrá tender las redes entre el sistema literario y el vasto campo de la cultura" (Clark de Lara: 63).

Para definir, por tanto, un género decimonónico es ineludible partir de este precepto teórico: su miscelánea de discursos. De lo que se deriva que el género fantástico del siglo XIX requiere un deslinde con respecto a otras nociones vecinas, como podrían ser lo maravilloso, la leyenda, lo gótico, lo milagroso y, en el autor que estudio, el espiritismo.

Además, el surgimiento de una literatura decimonónica de corte fantástico, no mimética o con tendencias a la irrealidad, procedió de las condiciones que el mismo positivismo y otras exposiciones científicas que estaban en boga imponían a los nuevos rumbos del conocimiento, según los cuales la evidencia experimental desmitificaría muchas nociones y supersticiones de la realidad. En ese contexto, el positivismo, derivado del proceso de secularización iniciado por la llustración como impulso de innovación y progreso, concluyó en una postura sociopolítica plenamente identificada con la tecnología, el método científico y en una certeza racionalista que comenzó a imponerse como el principio más válido para entender la realidad, lo que derivó en un desprestigio de las explicaciones de la religión cristiana que poco a poco se fueron convirtiendo en un mito más. El nuevo emblema de la verdad sobre el mundo nació, así, con la solidez científica propugnada por el positivismo y no por los atributos éticos y morales de la religión. Al respecto, Dolores López Martín opina:

En el XIx, época en que prima la desmiraculización y secularización del mundo, la fenomenología de lo fantástico nace de una relación de tirantez-acuerdo en- 
tre elementos de filosofía, la mitología, la religión, el iluminismo, la psicología patológica, y sobre todo, de la mediación sobre la relación del hombre sensible y lo suprasensible en el momento en que ya ni la fe, ni la razón, ni la ciencia, ni la técnica, son capaces de dar una respuesta satisfactoria a los interrogantes del hombre sobre la vida y la muerte (López: 39).

La literatura cumplió entonces la función de encauzar, desmentir, cuestionar y aclarar las supersticiones y los temores, como una respuesta del progreso científico y moderno del hombre finisecular. Aquí fue donde inició el auge de los textos que postulaban sistemas de mundo irreales, no miméticos.

Quizá como vehículo para la diseminación del positivismo (y del espiritismo más adelante), la literatura asumió esa doctrina ideológica como medio de propaganda, pero también como asunto, si no inherente, sí notorio, de una nueva modulación narrativa: el cuento fantástico decimonónico. Sobre este género, Tzvetan Todorov comienza la discusión y llama "clásico" al cuento fantástico decimonónico y Ana González Salvador, por poner otro ejemplo, lo Ilama relato "tradicional". Todorov apunta, además, que en este tipo de textos no hay choque entre dos realidades. No hay, entonces, ruptura con lo cotidiano, sino una perplejidad ante lo insólito, pues "lo fantástico es la vacilación experimentada por un ser que no conoce más que las leyes naturales, frente a un acontecimiento aparentemente sobrenatural" (Todorov: 24). En el momento en el que lo sobrenatural se asimila como parte de la realidad narrada, es decir, "Io sobrenatural aceptado", asienta el crítico francohúngaro (37), ya estamos ante otra formulación genérica: lo maravilloso, que es finalmente al que se adscribe Mancera, como se verá en el presente análisis.

La estructura propuesta por Todorov se aprecia en "Caridad" del siguiente modo: un forastero llega a un pueblo, en donde se contaba la leyenda de que el castillo feudal abandonado que se hallaba cerca del poblado estaba embrujado. Toda la gente aseguraba que cada noche se aparecían allí los antiguos dueños, unos individuos malvados, violentos y egoístas que habían hecho mucho daño a los vecinos, pero que Dios, por justicia divina, los había castigado convirtiéndolos en almas en pena. Motivado por lo que concibe como un chisme sin fundamentos, el foras- 
tero decide visitar el castillo y desmentir las leyendas absurdas, según él, sobre la vieja edificación. La realidad enfrentada en el lugar le hará variar drásticamente su opinión: los fantasmas sí existen.

Como postula Todorov, desde el principio se anuncia un hecho con carácter sobrenatural, que en el resto del texto sólo se profundizará conforme avance la trama. Lo primero que destaca es que el relato se autodenomina, sin titubeos, leyenda popular, y presume tener un sustrato real y auténtico, en la que se reúnen, sin embargo, todas las creencias y los prejuicios de los pueblerinos: "De generación en generación se ha transmitido la tradicional leyenda de aquella fortaleza, y la cual dista mucho de ser una fábula forjada con más o menos urdimbres de imaginación, para amedrentar a los chiquillos [...] o para entretener la velada, sino que es una verdadera y estupenda historia" (Mancera: 177). El narrador, a su vez, toma el papel del transmisor de la leyenda, una historia que él encontró por casualidad entre unos documentos viejos que había en su casa: "leí esa narración escrita con caracteres antiguos y con cuya hoja tropezaron mis manos alguna vez que me hallaba revolviendo el archivo de uno de mis antepasados" (177). El hallazgo del manuscrito viejo e incompleto es un tópico literario, no sólo de la leyenda y la literatura gótica, sino también de muchos otros géneros. Aquí funciona para validar la perspectiva supuestamente objetiva del narrador, su distancia del hecho referido.

Desde el principio se menciona el elemento sobrenatural: un castillo embrujado. Con una prosa de indudables tintes poéticos, que remiten asimismo a una marcada influencia gótica; Mancera describe así el viejo edificio:

Pavoroso y sombrío, fuertemente sombrío, era el espectáculo que en la oscuridad de la noche o a la misteriosa pálida luz de las estrellas, que como inconmensurable volcamiento de marmaja brillan en la anchurosa bóveda del cielo, presentaba al retardado viajero, el vetusto y feudal castillo derruido, sobre cuyos carcomidos muros, escalados aquí y allá por las parasitarias, merced a los años y a las lluvias, dos centurias habíanse abatido con su polvo y sus estragos (Mancera: 175).

La descripción del ambiente se justifica porque el gótico "no podía surgir sino en un contexto racionalista y en un país donde imperaba la 
Reforma: significa[ba] el primer intento de dominar la creencia mediante la historia, y lo sobrenatural mediante una escritura al fin consciente de los imperativos de lo real" (González Salvador: 209). Por esta razón, entonces, la ambientación del lugar responde al estilo gótico, que además es el idóneo por su confección de atmósferas fantasmagóricas, oscuras y tenebrosas, para retratar el asunto principal del cuento: una leyenda de fantasmas.

El personaje protagonista es un forastero, Ilamado don Diego de Hebromar, un joven soldado, curioso y aventurero, que se describe en los siguientes términos:

Fue el caso que por aquellos tiempos acertó a pasar un forastero, vestido con su aljuba, encerrado en armadura férrea, jinete en brioso corcel y armado de pies a cabeza, frente al sitio de la fantástica leyenda, y hubo de llamarle profundamente la atención la tosca lápida esculpida y pringosa, en la que se pedían oraciones para la familia noble de Von-Vaudreuil; e imaginando que en ello habría algo de raro y misterioso, propúsose averiguarlo tan luego como hiciese escala en la aldea más inmediata (Mancera: 179-180).

El joven soldado se siente, incluso, un Quijote, que va a indagar y a descubrir hechos asombrosos:

Su curiosidad se había interesado y sin saber por qué, sospechaba una nueva aventura propia de la antigua caballería andante y en la cual tuviese él que "desfacer agravios o enderezar algún entuerto"; y entusiasmado con la idea, una tarde de lluvias y de incendios en el cielo, cerca del oscurecer, montó en su caballo y saliendo del pueblo [...] tomó al galope la guijarrosa vereda que conducía al feudal castillo, sin que hubiesen sido parte a disuadirlo de su temeraria empresa las estentóreas voces con que algunos vecinos [...] le gritaban y le advertían que se volviese atrás [...] si tenía en alguna estima su vida (182).

El viaje adquiere un sentido simbólico que representa la travesía hacia lo secreto, hacia lo que nunca ha sido revelado, en este caso, el viaje que emprende el soldado al viejo castillo. Cuando entra a la fortaleza abandonada, don Diego se enfrenta a algo inesperado para una mente tan incrédula como la suya: "dentro del castillo, inundado en sombras, no tuvo ya voluntad propia; se sintió atraído y manejado por una fuerza extraña de la cual no pudo arrancarse, que lo condujo en la oscuridad; sentía que un 
soplo ardiente y pesado le quemaba el rostro y que su cerebro estallaba"; entonces, contra todo lo que antes había creído, el personaje se vio envuelto en un ataque de fantasmas:

Sintió brazos que lo sujetaban y manos heladas que lo abofeteaban y que lo hicieron rodar por el suelo [...] desenvainado su filoso alfanje se puso a repartir tajos por todos lados, pero aquellos golpes sólo herían el vacío [...]; y caía el infeliz don Diego y lo levantaban a prodigiosa altura para hacerlo caer de nuevo y golpearlo más y más; luego, ya exhausto, ya casi moribundo, fue bruscamente desprendido del suelo como si fuera una pluma [...] y encontrose de repente, trastornado por el vértigo en presencia de tres ataúdes (198).

Sin saberlo, el joven soldado había sido conducido a la tumba de los antiguos dueños del castillo y ahí presenció el último hecho que puede ser juzgado de sobrenatural: vio el espíritu de una mujer de blanco, con un halo luminoso que entró en la estancia y que con su sola presencia destruyó a todos los espectros malvados; luego con lentitud se acercó a don Diego y le contó al oído la historia de sus hijos muertos, de sus pecados y sus vicios, y le pidió desenterrar un gran tesoro escondido en el sótano para construir, una vez derrumbada la fortaleza, hospitales, talleres y casas de beneficencia para así descargar la culpa de sus hijos pecadores. El forastero lo promete y así termina la historia de las apariciones fantasmales. Entonces vuelve a tomar la voz el narrador y dice:

Y no es esa leyenda una urdimbre de imaginación para amedrentar a los chiquillos, pues que el espiritismo, las manifestaciones del alma en el mundo corpóreo han sido de todos los tiempos, y de medio siglo acá sus sectarios van en aumento y las experiencias y formas de fenómenos se multiplican al infinito [...]. Las aventuras que corrió esa noche aquel investigador —Don Diego de Hebromar- no parecerán sobrenaturales al lector si ha hojeado alguna vez los libros de Eugen Nus, William Crookes, Gabriel Delanne, Gibier y otros, o ha recorrido tantos y tantos periódicos que sobre la materia se publican en varios puntos de Europa (201-202; cursivas mías).

Todos los nombres referidos en la cita son pensadores que escribieron y defendieron la doctrina espírita. Con estas menciones comienza a desarrollarse la justificación de orden espiritista, esa tendencia decimonónica, 
también admitida como nueva religión (Edelman: 40), que conjugaba la filosofía con el cientificismo — sobre todo en su empleo del método experimental para cuestiones metafísicas-, que llegó a considerarse una corriente legítima de la ciencia, según sus adeptos (para otros, pseudociencia), y fue muy aceptada y difundida en las últimas décadas del siglo XIX.

De acuerdo con esta estructura, primero se narró el hecho sobrenatural y luego el narrador esclareció su sentido. Es así como el cuento de Mancera tiene como presupuesto narrativo la necesidad de ofrecer una explicación objetiva y racional, que concuerda puntualmente con la visión positivista de su momento histórico. Para él no parece suficiente el develamiento del fenómeno extraordinario, sino que éste es el pretexto para desplegar el significado de ese otro mundo paralelo al cotidiano. Ésa es la función del excurso final, que además puede leerse como una suerte de preceptiva del autor, ya que ahí se expresan sus inclinaciones literarias y su interpretación del cuento. Este excurso es un testimonio autoral de la búsqueda de referentes genéricos y de identificación textual que tenía Mancera como creador.

Desde el comienzo del texto, la historia narrada incita la interrogante de la posible existencia de los fantasmas o de los seres de otro mundo. Ésa sería su duda fantástica. El evento sobrenatural y el final del cuento responden a la incertidumbre inicial sobre otras realidades y otros seres. En este punto es cuando se verifica el concepto de "realista" con que el autor denominó su libro. Esta misma idea la admite el propio narrador cuando afirma: "aunque lo relatado en CARIDAD fuese una invención, nada tiene fuera de lo verosímil y de lo que ya es sabido que se verifica en el mundo supraterrestre" (Mancera: 202; cursivas mías); es decir, es una historia realista porque tiene una visión de mundo que se asume como tal. No hay, pues, dos realidades antagónicas, sino dos realidades complementarias y consideradas verdaderas que se conectan al momento en el que se aceptan las leyes espiritistas del funcionamiento de la materia. Esto revela también por qué Heriberto Frías aventuraba en el prólogo que en Cuentos diáfanos "no hay ficción" (Frías ápud Mancera: VI).

El final, además, es el espacio para mostrar la última palabra del narrador, en donde él, con su conocimiento, puede reestablecer la permanencia de un orden a partir del esclarecimiento del enigma. Por tanto, hay 
un juego con la racionalidad e, incluso, con las ideas emitidas por las instituciones religiosas cristianas. Éste es su punto más relevante. Por eso, el personaje protagonista se interpreta como testigo, un investigador, y el narrador como un ser racional e informado que tomó esta leyenda como asunto de reflexión y como pretexto para sustentar la eficacia científica del espiritismo y para difundir su doctrina. Acerca de este asunto, José Ricardo Chaves anota que uno de los principales intereses del espiritismo era proporcionar "una comprobación científica de la vida post mortem y, sobre todo, de la comunicación con los difuntos" (Chaves 2005: 53), asunto que, en efecto, se puede verificar en el cuento de Mancera.

Ahora bien, en "Caridad" no se enfrentan dos realidades, no hay inestabilidad de lo real ni una franja conflictiva, como sucede en los relatos fantásticos del siglo xx, pues la realidad narrada está mezclada con otra supraterrenal; por este motivo, se aceptan sin mucho conflicto las leyes de ese mundo en apariencia desconocido y se legitima como auténtico; al mismo tiempo, el narrador sugiere la aceptación de otros sistemas alternativos y paralelos que habían permanecido ignorados. Esta definición se inclina a lo maravilloso, como categoría genérica colindante a lo fantástico, pues este último aquí pierde validez como estructura funcional del relato por el hecho de que el narrador asumió la tarea de justificar la anécdota.

El enfrentamiento no es, pues, entre realidades, sino entre dos creencias o dos métodos de conocimiento, a saber: conocimiento vs. creencia; fe vs. escepticismo; natural vs. sobrenatural; superstición vs. espiritismo. Por ello, el narrador acredita el conocimiento espiritista como un sustento científico de racionalidad, que sirve para explicar lo que en apariencia es irracional. De esta manera, está proponiendo una defensa de esa propuesta científica, que para él es incuestionable y confiable.

En palabras de Ana González Salvador, se narra "la historia de una transgresión" (217); en este caso, la vida después de la muerte, que en el cuento se probaba con la existencia de los espíritus luego de la expiración; esto es, de las almas en pena de los viejos herederos del castillo, quienes aún deambulan por la fortaleza abandonada en busca de venganza. La transgresión expuesta por Mancera operaría en el plano de las creencias al denunciar hechos que atentan contra las leyes del mundo objetivo, pero que se defienden como legítimos; es, en cierto modo, un desafío a la razón 
y a sus métodos de dilucidación de la inmaterialidad del alma, pero también constituye una postura ante la literatura de carácter fantástico, porque amplía el paradigma de realidad dentro del texto y se configura más bien como literatura maravillosa, ya que se justificó lo sobrenatural mediante el espiritismo. Esta intención se observa desde la descripción del pueblo, que representa la superstición, y la del personaje protagonista, que simboliza la razón, y es por ello que se comporta como un incrédulo que se burla de las creencias populares, que para él eran "una profunda, pero vulgar y absurda preocupación". Don Diego es un hombre que tiende más a lo racional y, por eso, prefiere comprobar en persona la invención de estas leyendas, pero al llegar al castillo su visión cambia y se desploma ante la turbación de las circunstancias. En el texto, el terror se asocia a lo desconocido, pero una vez explicado el fenómeno sobrenatural, se diluye del todo el miedo experimentado por el protagonista. El narrador tiene la función de mediador entre esos dos polos. De manera que, mediante el conocimiento y el esclarecimiento espiritista, las fronteras del terror y el miedo como agentes de la amenaza desaparecen. Lo tenebroso, por tanto, se entendía sólo como objeto de discernimiento: si había terror, entonces tenía que haber también una explicación razonada; en esta ocasión, el narrador acude al espiritismo, que para él corresponde al plano de lo científico, con lo que pretende demostrar que las almas existen más allá de la materia humana que las posee en vida.

Como se puede ver, este enfoque del narrador sirve para evidenciar que "Caridad" pertenece a un campo vecino de lo fantástico. Sigo aquí la idea de José Ricardo Chaves de que la literatura decimonónica de los espiritistas es una desviación de lo fantástico, pues es "un fantástico endeble quizá, un modo más que un género en busca de definición" (Chaves 2013:15). Se tiene la necesidad teórica, no obstante, de encontrar esa definición, una definición que reconozca la naturaleza discursiva de ese tipo de relatos con presupuestos científicos/espiritistas y con un sistema narrativo propio.

Conviene precisar que Mancera llama fantástico a un texto en el que cualquier ruptura de las leyes que gobiernan el mundo objetivo puede ser comprendida, sin el conocimiento espiritista, como un fenómeno sobrenatural. Concibe además lo fantástico como un asunto temático en el que interviene un objeto o entidad al margen de la experiencia humana co- 
rriente y mimética — definición que en realidad aplica para la mayoría de los textos decimonónicos que se intitulan "fantásticos"—. Éste adquiere, entonces, sólo un sentido semántico que no repercute en la estructura ni en la sintaxis del discurso. En términos genéricos, lo que destaca es que lo fantástico, según el propio autor lo entiende, sigue las reglas de funcionamiento de realidad empíricamente comprobables, por lo que podríamos designarlo, de forma paradójica, "Realismo fantástico". Puesto que no existe un término que delimite esta particular formulación, me parece más pertinente llamarlo "Realismo espiritista", como una subcategoría del género maravilloso que consiste en un texto en el que lo maravilloso, en cuanto género discursivo dominante, está vinculado con el espiritismo; es decir, que lo sobrenatural emerge a partir de la presencia de las almas que, según lo trazado en el cuento, existen dentro del paradigma de realidad aceptado. Esta característica se basa en los preceptos que defendían que las apariciones eran verificables y reales, por lo que, siguiendo esos mismos preceptos, en los relatos la realidad "se ensancha" y permite dar cobijo a otras causas y elucidaciones de los fenómenos anormales. Utilizo el término realismo con el sentido de configuración textual —es decir, no aludo a la corriente estética que lleva el mismo nombre — de una realidad en una obra artística; una realidad sometida a un trabajo de ordenación del lenguaje, y que en esa medida elabora un mundo cerrado y autónomo. Lo relevante, por ende, en estos textos de Mancera es el estatuto de lo real y su confrontación con su opuesto: la irrealidad.

Lo que denomino "Realismo espiritista" sería, entonces, un género histórico, datado a finales del siglo xIx. Dicha conceptualización no está peleada con la ciencia, al contrario, la toma como fuente temática y paradigma. Mi definición deriva, de hecho, de una propuesta que Todorov brindó respecto a la literatura francesa decimonónica; me refiero a su concepto de "maravilloso científico", que el crítico expone con las siguientes palabras: "Aquí lo sobrenatural está explicado de manera racional, pero a partir de leyes que la ciencia contemporánea no reconoce. En la época del relato fantástico, lo que pertenece a lo maravilloso científico son las historias en las que interviene el magnetismo. El magnetismo explica 'científicamente' acontecimientos sobrenaturales" (Todorov: 48). El magnetismo era uno de los instrumentos científicos del espiritismo, de ahí que 
el concepto de Todorov y el mío sean cercanos: el realismo espiritista es un tipo de enunciación del maravilloso científico, pero debido a su especificidad "espírita" considero más conveniente definirlo como "realismo", porque así se postula en el texto y así era tomado por los partidarios de esta doctrina del pensamiento; esto es: como una realidad auténtica y como un sistema de mundo verificable.

Por último, aunque el terror y el miedo no son requisitos necesarios para el género, en "Caridad" sí cumplen una función: son el detonante que obliga a buscar el sentido de las cosas ignoradas por la certeza racionalista. Ambos son, por ello, recursos narrativos que se emplean para elaborar la trama y para inclinar las expectativas de los personajes. Primero, el pueblo entero vive con miedo y, después, el propio protagonista lo experimenta, pero el argumento que provee el narrador como apéndice muestra que el terror sólo existía porque era un efecto de lo desconocido: era la ignorancia que se tenía respecto a esa otra condición de la realidad, que consiste en la vida del alma más allá de la materia.

\section{"Un crimen": otro caso de espiritismo literario}

El segundo cuento del libro anunciado como fantástico lleva el título de "Un crimen". La anécdota narrada es muy sencilla: un hombre de mediana edad, buen padre, trabajador eficiente, honrado y humilde, se interna en el bosque para pensar en todos los problemas económicos que lo torturan, que son muchos. Ahí encuentra una fonda miserable y entra, pide una comida frugal y una cama para pasar la noche. Después de meditar sobre las cualidades económicas del invitado, los dueños del hostal deciden matarlo, pues lo confunden con un catrín adinerado; lo asesinan cruelmente y esconden su cadáver en el fondo de un pantano nauseabundo. Seis meses de investigación han transcurrido desde el crimen y nada se sabe del humilde empleado. Una noche, un sabio, sólo identificado en el texto como Sr. R., tiene la aparición de un alma en pena que le descubre el misterio de un homicidio, que por supuesto es la del hombre asesinado en el hostal. Como resultado de esta revelación, se encuentra el cadáver y los asesinos van a prisión. Al final, el mundo vuelve a su aparente orden y la justicia social se efectúa. 
Cómo se narró este asesinato y qué significa la aparición fantasmal del muerto en el parámetro de realidad trazado en el relato son las dos preguntas que pretendo responder para verificar la cualidad fantástica o maravillosa de "Un crimen".

El cuento inicia con la vida y los sentimientos del empleado asesinado. En un ambiente con toques románticos, y esto es muy importante, se describe la historia de ese pobre hombre. Así se expresa el narrador:

Y hubo un día, fue un tiempo, como dicen los cuentos, en el que deseando vagar a solas con sus tristezas y sus miserias, deseando no oír más por algunas horas el impertinente llanto contristador de sus chiquillos que tenían hambre ni ver el semblante de madona afligida, de su resignada esposa, un joven, empleado y con escasa dotación de sueldo, venido a menos, pero de la buena sociedad [...] se internó en el bosque marchando automáticamente, sin rumbo fijo y sólo con el pensamiento de sus melancolías, de sus deudas y sacrificios (Mancera: 34).

El joven caminó durante horas hasta que lo alcanzó la noche en medio del bosque, que como bien sabemos según la tradición gótica de la literatura y de los cuentos de hadas, es uno de los lugares propicios para el crimen, la aventura, el misterio, lo sobrenatural, etc. El escenario se describe en el texto como sigue: "viose rodeado por los anchos pliegues de tinieblas de la noche; perdido en la soledad del bosque umbroso, intrincado e imponente con sus árboles vetustos de frentes venerables y las grietas de sus rocas" (35); en ese lugar de aislamiento y oscuridad, de pronto "vislumbró a lo lejos la luz del farol empañado y mortecino, con el mismo tenue brillo de una estrella colocada en la inmensidad" (35). Era una humilde choza que servía como fonda y hostal para los viajeros; un lugar mal alumbrado, apestoso, mohoso "que corría parejas con la miseria y suciedad" (37). Desde este momento, el aspecto del hostal despierta la desconfianza y el temor del joven, quien armándose de valor se hospeda ahí y se acuesta para, poco después, quedar dormido profundamente. Luego se indicará que durmió con total placidez debido a que fue envenenado con una pócima que estimulaba el sueño.

Hasta esta escena no ha ocurrido ningún evento sobrenatural. Todo parece propicio, más bien, para el crimen y la maldad, pues los mismos 
caseros están expuestos con rasgos negativos: la mujer es una matrona fea, malhumorada y salvaje que incluso es Ilamada bruja; su esposo, un hombre robusto, grosero, de aspecto vulgar y violento. El narrador los dibuja como una "pareja tétrica y fantástica" (39). Aquí el adjetivo "fantástico" está utilizado con el sentido de quimérico, fantasmagórico e ilusorio. No remite, por supuesto, al género literario. Esta definición, de hecho, es operativa para todas las veces que Mancera usa el término como adjetivo. El texto presenta, pues, hasta esta parte, un funcionamiento de la realidad que remite sin problemas a los fundamentos del realismo como categoría literaria, pero también al género fantástico, si se sigue la idea de que en la narración se "crea una ilusión de realidad, acumulando detalles que por ser miméticos contribuyen a hacer sólido el mundo que se plantea como cotidiano dentro del texto" (Morales y Sardiñas: 30), tal como se había esbozado en "Caridad".

Estos dos personajes planean el robo y el homicidio con prontitud, y el acto se lleva a cabo con una actitud sangrienta e inhumana: "se acercó al lecho armado de su cortante hacha y como si tronchase un débil tronco, de un solo golpe partió en dos, despedazándolo, el cráneo del infeliz que dormía tan confiada y profundamente" (Mancera: 39). Luego esconden el cadáver en "el foso de agua vetuminosa [bituminosa] que, después de ondular un momento, agitada y estremecida, como en protesta de esa infamia, recobró su silenciosa calma y su impenetrabilidad acostumbrada" (39). Consumado el crimen, no quedan rastros del delito. Hasta aquí el cuento nos ha contado sin fluctuaciones ni dudas de ningún tipo la historia de un asesinato.

Era necesario mostrar ese mundo casi inflexible de normas para que pudiera causar conmoción la ruptura de leyes que se presentará más adelante, pues, en efecto, el episodio en que se puede notar un quiebre con la realidad, hasta este momento formulada con un carácter realista, incluso naturalista debido a la crudeza de las descripciones, es cuando el Sr. R. tiene un encuentro sobrenatural con un alma en pena: "No asustado, pero grandemente sorprendido y horrorizado, notó que la pieza estaba iluminada como con una luz fosfórica y frente a él [estaba] un hombre demacrado y vestido de negro, con la cabeza hecha pedazos, abierta como una granada, chorreando sesos y sangre y con los ojos, en los que se retrataba el 
más cruel de los dolores, despidiendo rayos de odio y de venganza" (43). El Sr. R., ecuánime a pesar del horror de la presencia, pregunta a la aparición quién es y qué desea; entonces el difunto declara las circunstancias perversas de su muerte y exige una retribución de justicia ante la sociedad. El diálogo entablado entre el vivo y el muerto transcurre en total paz, sin alteraciones, salvo la sorpresa del principio. El Sr. R., al otro día, va a la policía, expone su visión, que al principio es puesta en duda, y reclama se revise la fonda y el pantano. Atraídos por el morbo, los judiciales obedecen e interrogan a los culpables, que finalmente confiesan su culpa. El cuerpo de delito, como dice el narrador, es extraído del agua putrefacta y el cuento concluye sin más, sin acotaciones o defensas de ningún tipo.

Como puede notarse, primero se narró el asesinato, después la aparición fantasmal y, por último, la resolución del misterio, casi en el orden narrativo habitual de la literatura policiaca o en el género de lo extraño. El cuento escrito por Mancera parece tener como presupuesto discursivo el imperativo de una explicación racional de los misterios de la sociedad, en este caso, de un crimen. La aparición fantasmal en el relato es el pretexto para desplegar el significado de ese otro mundo paralelo al cotidiano, basado en el espiritismo, que es su fundamento científico, según el texto, con el cual se puede beneficiar a la sociedad, en la medida en que es un recurso que contribuye a la calidad de vida de los individuos; era conveniente, sin embargo, presentar, primero, un mundo en apariencia legal y que sigue una normatividad cotidiana para que el fenómeno fantasmagórico causara una ilegalidad en ese sistema; ilegalidad que será asumida como verídica, como legítima en la lógica de realidad, que ahora pertenece a otro paradigma: un mundo en donde sí existen los fantasmas. La constatación del hecho sobrenatural reemplaza un sistema de realidad por otro. Los personajes testificaron esta transformación de visiones, sobre todo el Sr. R. Estamos, de nuevo, ante una construcción y sintaxis narrativas que se ajusta a una singular enunciación del género maravilloso.

La historia admite, entonces, la existencia de los fantasmas o de los seres de otro mundo. En este punto es cuando se verifica el concepto de "realismo". Dicha idea la suscribe el propio narrador cuando opina: "quien haya leído o crea en el espiritismo, y creerá por haber leído, no hallará en esto nada excepcional" (Mancera: 42-43); es decir, es una his- 
toria realista porque tiene una visión de mundo que al final del relato el narrador y los personajes juzgan realista, de modo que no hay dos realidades incompatibles, sino una sola, pero habitada por fantasmas. Es así que el cuento, al descalificarse la duda, se aleja de la literatura fantástica, la cual sí exige la vacilación como recurso indispensable. En "Un crimen" hay conciliación de mundos opuestos, a pesar de la supuesta ruptura de la lógica cotidiana, pero mediante un juego con la racionalidad e, incluso, con las ideas emitidas por la ciencia y por las instituciones religiosas cristianas, se llega a la conclusión de que la existencia humana no había sido comprendida en su totalidad, faltaba conocer la vida de otros entes y elementos desconocidos: los espíritus. Así, el espiritismo parece garantizar las herramientas científicas más eficaces para el conocimiento, porque brinda respuestas a sucesos jamás descifrados.

Es relevante precisar que la propuesta de Mancera no cabe dentro del concepto de lo maravilloso puro, puesto que "éste produce, la mayoría de las veces implícitamente, sus propias condiciones de funcionamiento, apartado de toda consideración sobre lo real objetivo" (Bellemin-Noël: 109). En los dos cuentos que he analizado sí hay un choque entre una realidad, que responde a un paradigma realista, y otra que es ajena, pero que acabará por ser aceptada como parte del mundo establecido en el discurso. Además, en ningún momento se presentó una crisis de razón que obligara a los personajes a dudar de su capacidad para comprender o percibir el mundo tal como se les ofrecía, como sí ocurre en los textos fantásticos. La introducción del elemento extraordinario provocó admiración, sorpresa y miedo, reacción perfectamente codificable por lo maravilloso y que se produce como reacción a la anormalidad y a "lo nunca visto" (Morales 2007: 163).

Por último, el realismo espiritista que propongo como subdivisión genérica para analizar este tipo de textos no debe ser confundido con la ciencia ficción, pues a pesar de que se basa en un presupuesto científico, éste se circunscribe al carácter espiritista de aquellos discursos aceptados como científicos a finales del siglo xIx. Para Mancera, sus textos revelan una realidad con espíritus, y de ahí procede la acepción de la terminología teórica que uso para sus cuentos, que, sin ser enteramente maravillosos, tampoco son realistas en su totalidad. ¿Qué tipo de textos son entonces? 
Propongo explicarlos como relatos que presentan la configuración textual de una realidad perturbada por fantasmas que rompen el orden cotidiano, pero que tienen como modelo de legalidad y como comprobación de ese mundo los parámetros científicos y las creencias del espiritismo decimonónico, de tal forma que género y temas se unen para configurar una nueva categoría literaria.

\section{Reflexión final}

Aunque lo fantástico puede ser entendido como un asunto temático relacionado con los fantasmas — como se sabe, el tema no hace el género-, el proceso de transgresión narrado y la disquisición entre dos realidades enfrentadas, primero en lucha y luego en conciliación, permiten observar que en los relatos sí hay una ilegalidad que actúa en la narración con el carácter de choque y vacilación, como un atentado contra la lógica del mundo conocido por los personajes dentro de la diégesis; a causa de esta gran diferencia, es pertinente definir ese tipo de obras con otra terminología teórica. En primer lugar, hay que considerarlas parte de los discursos de irrealidad, ese gran campo teórico que clasifica los textos con base en la cualidad verídica o imposible de sus historias, en oposición al realismo como argumento discursivo y como sistema de mundo textual; $y$, en segundo, se trata de cuentos en los que la discursividad opera con miras a un cuestionamiento diferente - aunque con recursos narrativos similares en algunos aspectos al género fantástico-, que sirve para configurar una trama a partir de un principio narrativo en el que la realidad está enfrentada a las creencias, a las supersticiones y a la ciencia. Ahí está su cuestionamiento esencial. Se puede concluir, provisionalmente, que Mancera llamaba fantástico al género narrativo en el que la aparición de fantasmas permitía deliberar sobre la naturaleza racional y científica del concepto de realidad, pero sus textos, como artefacto genérico, funcionan más bien con estructuras, sintaxis y descripciones procedentes del género maravilloso. En su vertiente espiritista, la literatura decimonónica tomó ruta en una nueva enunciación discursiva, que mediaba entre lo maraviIloso, como su modalidad genérica, y lo fantástico como atributo temático (el fantasma y las atmósferas fantasmagóricas). 


\section{Bibliohemerografía}

Bellemin-Noël, Jean. "Notas sobre lo fantástico (textos de Théophile Gautier)", en Teorías de lo fantástico. Introd., comp. de textos y bibliografía de David Roas. México: Arco / Libros, 2001.

Chaves, José Ricardo. "Espiritismo y literatura en México", en Literatura Mexicana. Ciudad de México, VI-2 (julio-diciembre 2005): 51-60.

Chaves, José Ricardo. México heterodoxo. Diversidad religiosa en las letras del siglo XIX y comienzos del XX. México: Bonilla Artigas / Universidad Nacional Autónoma de México, 2013.

CLARK DE LARA, BelEM. Letras mexicanas del siglo XIX: modelo de comprensión histórica. México: Universidad Nacional Autónoma de México, 2009.

Edelman, Nicole. "Lo oculto y las terapéuticas espiritistas del espíritu y del cuerpo en Francia (1850-1914): de la creencia al saber y vuelta", en Asclepio. Revista de Historia de la Medicina y de la Ciencia. Madrid, LVIII, núm. 2 (juliodiciembre 2006): 39-62.

GonZÁlez Salvador, ANA. "De lo fantástico y de la literatura fantástica", en Anuario de Estudios Filológicos. Extremadura, VII (1984): 207-226.

LÓPEZ MARTíN, DOlORES. "El espiritismo, la parapsicología y el cuento fantástico hispanoamericano del siglo XIX", en Arrabal. Lérida, núms. 5-6 (2007): 39-46.

Mancera, Octavio. Cuentos diáfanos (Cuadros realistas). México: Biblioteca de "La Revista Militar Mexicana", 1897.

Morales, Ana María y José Miguel Sardiñas (eds.). Odiseas de lo fantástico. México: Ediciones de los Coloquios Internacionales de Literatura Fantástica, 2004.

MORAles, ANa María. "Credibilidad, percepción y reacción: los vaivenes de lo maravilloso a lo fantástico", en Ana María Morales y José Miguel Sardiñas (eds.), Rumbos de lo fantástico. Actualidad e historia. Palencia: Ediciones Cálamo, 2007. 155-177.

TODOROv, Tzvetan. Introducción a la literatura fantástica. México: Ediciones Coyoacán, 2005.

\section{Diana Vanessa Geraldo CamaCho}

Doctora en Literatura Hispánica por El Colegio de México y Maestra en Literatura Hispanoamericana por la Universidad de Sonora. Algunos de sus trabajos más recientes son: "La narrativa breve de Vicente Riva Palacio en El Liberal (Madrid, 1892-1895)", en (an)ecdótica (IIFL, UNAM); "Las aventuras del folletín en Monja y casada, virgen y mártir de Vicente Riva Palacio", en Itinerarios (Universidad de Varsovia, Polonia), y "La novela histórica colo- 
nial a través de los siglos: Ángeles del abismo de Enrique Serna y Monja y casada, virgen y mártir de Vicente Riva Palacio", en Semiosis (Universidad Veracruzana). Actualmente se desempeña como Investigadora en el Seminario de Edición Crítica de Textos, en el Instituto de Investigaciones Filológicas de la UNAM, en donde está elaborando la edición crítica de la Narrativa breve de Vicente Riva Palacio. 